https://doi.org/10.48009/2_iis_2005_3-9

\title{
A FRAMEWORK FOR THE DEVELOPMENT OF COLLABORATIVE COMMERCE APPLICATIONS
}

\author{
Kazuo Nakatani, Florida Gulf Coast University, knakatan@fgcu.edu \\ Ta-Tao Chuang, Gonzaga University, chuang@gonzaga.edu
}

\begin{abstract}
This paper presents a framework for the development of collaborative commerce applications that integrates generic capabilities of collaborative technology and functional requirements of collaborative commerce. The framework was developed based on the classification of ccommerce-related technologies, systems, and collaborative functional requirements identified in the previous research studies. The paper also demonstrates the usefulness of the framework.
\end{abstract}

Keywords: collaborative commerce, c-commerce, e-commerce, knowledge management

\section{INTRODUCTION}

Collaboration with customers, suppliers and even competitors has been considered as a key to success or survival in the intensive competitive environment. As many different types of information systems have been used as strategic weapons or necessity, collaborative commerce (c-commerce) has been identified as a new type of e-commerce that can be used to create competitive advantage. A research study by Delloite Consulting shows that "the group of companies that leads in coupling business processes and information exchange across their trade partners deliver as much as 70 percent higher profitability than those organizations that do not integrate with trading partners" [9, p.1]. The same study also shows that c-commerce will be widely used by all sizes of companies by 2005 .

In spite that many successful stories of c-commerce applications have been reported in academic and trade journals as well as on the web, very few research studies have attempted to develop a theory-based framework that explains how c-commerce applications or applications with emphasis on inter-organizational collaboration should be developed [7] and those do not explicitly consider one important component of collaboration, knowledge management $[6,18,19$, $22]$. Knowledge management has been identified as one of the most critical components of ccommerce by several researchers $[3,14,20,23]$.

Considering the availability of independent but compatible components of c-commerce technologies and the importance of knowledge management, this research attempts to create a theory-based framework that illustrates how to integrate generic collaborative computing and knowledge sharing functions to develop a c-commerce application. The purpose of the framework is for evaluating the needs of c-commerce initiatives, integrating "generic" collaborative computing and knowledge sharing functions into a c-commerce system, and classifying the systems in segments. This framework helps researchers to understand how different components of c-commerce applications supporting particular types of collaborative activities. The framework also helps practitioners evaluate and integrate collaborative computing and knowledge sharing technologies into a particular c-commerce solution. By combining 
appropriate technologies, c-commerce application developers are able to use a modular approach to develop a c-commerce application for collaborative activities and reduce its complexity.

\section{LITERATURE REVIEW}

This section first reviews previous literature in the c-commerce, and collaborative computing, especially ones that explain taxonomy to understand what generic types of components are used to create different types of c-commerce applications. Also, the section reviews knowledge sharing and management taxonomy because it is one of the critical processes of c-commerce. Finally, the section reviews the literature regarding functional requirements of group collaborative activities. This review will be a basis to identify the functional requirements for ccommerce applications.

C-commerce is an advanced form of e-commerce and it coalesces around the information exchange and activity views, while the focus of e-commerce is on the trading view [14]. Furthermore, c-commerce does not ignore the effect views and value-chain view, which are the main focuses of e-business applications [14]. One study classifies c-commerce applications into three categories: (a) Product Life Cycle Management (which includes product design and development, design collaboration, and business process collaboration), (b) Supplier Relationship Management, and (c) Knowledge Management [3]. Another study used a similar approach and identified several collaborative activities where c-commerce can be used: collaborative planning and forecasting, product development, demand management, planning and scheduling, production management, sale support, vendor management, and order management [9]. Additionally, the evolution of c-commerce is classified into three stages: (a) web-enabled single-dimensional and single-process c-commerce, (b) B2B exchanges-based, single-dimensional and multiple-process c-commerce, and (c) web service-based, multipledimensional and multiple-process c-commerce [10]. Finally, another study classified the ccommerce applications into one that supports easy-to-structure, more transaction-oriented type activities through one that supports hard-to-structure, more knowledge and community oriented activities [2].

Collaborative computing is a core component of c-commerce. Collaborative computing is also a basis for groupware and knowledge management. One study developed a functional classification of collaborative systems [1]. In that study, the authors summarized the classification dimensions used in the previous literature. Those dimensions include (a) application time/space, (b) group issues (subcategories are types of group tasks, characteristics of groups, and group size), (c) technical (subcategories are scalability, software, and hardware), and (d) other (usability and ergonomics, and mode of interaction). Then, they reviews 47 systems using collaborative services provided by systems, and finally, they classified the systems into four functional categories using two dimensions of services (document sharing, document management, and synchronous work on files/documents are one dimension and the rest are the second dimension). Those four functional categories are group file and document handling, computer conferencing, electronic workplace, and electronic meeting systems. They also summarized the focal points of the four functional categories using time and space dimensions. Electronic meeting systems support both synchronous and asynchronous time dimensions as well 
as both co-located and remote space dimensions. The rest of the three are intended to support all but the co-located space dimension.

Another study examined how groupware technologies and theory affect collaborative problem solving in the context of software engineering [8]. In that study, the authors evaluated eight groupware tools that are specifically designed to support problem solving regarding the functionality of the tools that facilitate the foremost tasks that a group performs during the software development. They also evaluated nine general groupware tools that are designed to accommodate general collaboration regarding the functionality of the tools that facilitate collaborative effects. They concluded that software development groupware tools had more focus on technologies for collaboration and less focus on the methodology, ignoring psychological and sociological issues associated with collaborative problem solving. They suggested that tools should be designed from the psychological and sociological perspectives.

Knowledge management itself is a complex research topic. Here we review the literature to identify the roles of knowledge sharing and management in the context of c-commerce as well as generic technologies used for knowledge sharing and management. Knowledge management was treated as the third area where c-commerce applications could be applied [3]. In another study, knowledge management was treated as the third building block of c-commerce [20]. Another study differentiates collaboration from other types of group activities such as communication, cooperation and coordination and the unique characteristic of collaboration is to enhance the capacity of another for mutual benefit and to achieve a common purpose [13]. We believe that this "enhancement" is typically done though learning from each other. According to [20], the primary role of knowledge management in c-commerce is training through e-learning. Knowledge management helps transforming novice workers to knowledge workers and thus making an organization more cost-effective. Another study reviewed the previous knowledge management literature and classified knowledge management applications into six types, identified enabling technologies for each type and established their associations [4]. The result of this study was expanded by [12] and it associated the knowledge types (tacit and explicit) and the four knowledge transformation processes (socialisation; externalisation; combination; and internalisation) proposed by [16]. Another study [15] also identified examples of technologies that could be used in the four transformation processes proposed by [16]. Although their lists show some commonality, they are different, indicating the same technology can be used for more than one knowledge management activity. Additionally, document management system can be used as another technology to preserve valuable explicit knowledge and four types of sources stored in a knowledge directory can be used to find experts [15]. Knowledge discovery in databases using data mining is another technology used in knowledge management [21].

To develop a framework, we need to identify functional requirements of c-commerce applications for collaboration. What activities are taken in a group process is also a large research topic. We made an effort to identify those activities to be supported by information systems. Chandler [5] studied the collaborative work of the board members of an international professional organization when they were rewriting the organization's mission statement with support of asynchronous distributed tools such as e-mail and listserv. He found that they played mainly the roles of information seekers, information givers, evaluators, and encouragers; some of the conventional group roles proposed by [11]. He summarized that negotiation and coordination 
was critical for successful collaborative effort. He also summarized the advantages and disadvantages of asynchronous collaboration tools compared with synchronous collaboration tools. Asynchronous tools allow quick, relatively easy transfer of ideas and documents while participants continue to work on assignments individually. Another advantage of asynchronous tools is that it reduces a level of interpersonal interaction among conflicting members. Its disadvantages include more frequent confusion created from unexpected changes made by team members. Another disadvantage is that participants often forget what is going on and have difficult time to compensate for the lack of cues. Olson, Olson, Carter, and Storrosten [17] studied face-to-face meetings held by experienced professional software designers during the logical design phase of software design projects and identified collaborative activities they were engaged in during the meetings. Those activities are categorized to discussions regarding (a) Issue, (b) Alternative, (c) Criteria, (d) Project Management, (e) Meeting Management, (f) Summary, (g) Goal, (h) Walkthrough, (i) Other, (j) Digression, and (k) General and Artifact Clarification. The first nine categories were also further categorized into discussion of the topic itself and clarification regarding the topic. They included the coordination activity but excluded frequent informal contact outside the formal meetings and works done individually from their study. They concluded that design meetings they observed were representative of a range of meetings in which a small group solved intellectual problems and the above activities could be generalized to different context. We believe the integration of these two research findings is sufficient to be a basis for our framework, which will be presented in the next section.

\section{A FRAMEWORK FOR C-COMMERCE APPLICATION DEVELOPMENT}

In this section, we present our framework that illustrates a process of integrating "generic" collaborative computing and knowledge sharing functions identified in the literature review into a c-commerce application that meets a specific need of collaborative activities.

A definition of organizational collaboration is "a process in which organizations exchange information, alter activities, share resources and enhance each other's capacity for mutual benefit and a common purpose by sharing risks, responsibilities and rewards." [13, p. 22]. By synthesizing the literature review in the previous section, we take a stand point that c-commerce is a new type of e-commerce that uses collaborative computing and knowledge sharing/management technologies and whose goal is to support business activities performed by people in different functional areas of an organization or in different organizations by making transactional information and expert's knowledge and experts themselves readily available to other members and by managing the process of activities.

Figure 1 shows our framework for c-commerce application development. The bottom of the framework indicates that c-commerce applications are built on traditional e-commerce systems to share transaction information among collaborative group members. Collaborative activities are placed on a continuum ranging from structured activity/work flow management type function to unstructured problem and issue solving type function. Technologies and systems that could be used for those functional requirements are listed in the middle of the framework. There is no one-to-one match between functional requirement of collaborative activity and technology because many technologies can be used to fulfill the need of various functional requirements. Rather, this framework listed technologies and systems in the order that corresponds to the continuum of the function type. The right-hand part of the framework shows the focus of c- 
commerce applications built from integration of those technologies and systems. Toward the bottom of the framework, the c-commerce applications are more effective in coordinating work and activities among collaborative members. In the middle, the c-commerce applications are more effective in collaborative work or decision-making. Toward the top of the framework, the c-commerce applications are more effective in sharing and transferring knowledge among collaborative members. By integrating all of the technologies and systems, the full-integrated ccommerce applications could be built.

\begin{tabular}{|c|c|c|c|c|}
\hline $\begin{array}{l}\text { Collaborative Activity } \\
\text { Function Requirement }\end{array}$ & $\frac{\text { Function }}{\text { Type }}$ & $\frac{\text { Technologies and Systems Used in }}{\text { C-Commerce Applications }}$ & \multicolumn{2}{|c|}{$\begin{array}{l}\text { C-Commerce } \\
\text { App. Type }\end{array}$} \\
\hline $\begin{array}{l}\text { Issue \& conflict mgmt } \\
\text { Issue Clarification } \\
\text { Alternative } \\
\text { Alternative Clarification } \\
\text { Criteria } \\
\text { Criteria Clarification } \\
\text { Artifact mgmt \& Clarification } \\
\text { General Clarification } \\
\text { Encouragement/Digression } \\
\text { Walkthrough } \\
\text { Walkthrough Clarification } \\
\text { Summary } \\
\text { Summary Clarification } \\
\text { Gow............................... } \\
\text { Goal Clarification } \\
\text { Project Management } \\
\text { PM Clarification } \\
\text { Meeting Management (MM) } \\
\text { MM Clarification }\end{array}$ & 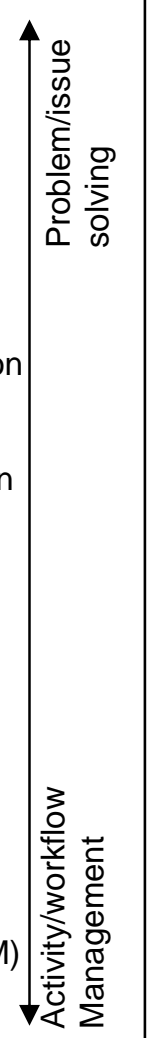 & $\begin{array}{l}\text { Knowledge management } \\
\text { Group decision support } \\
\text { Poling/survey } \\
\text { Discussion (Bulletin board) } \\
\text { Real-time talk (chat) } \\
\text { Video/audio conferencing } \\
\text { Group simultaneous authoring and revision } \\
\text { Shared workspace (and whiteboard) } \\
\text { Document/file management (DB) } \\
\text { Screen sharing (co-browsing) } \\
\text { Application sharing } \\
\text { Presentation capability } \\
\text { Shar............................................................................................ } \\
\text { Workflow management } \\
\text { (Email) Notification } \\
\text { Track project milestones/activities } \\
\text { To-do list } \\
\text { Address book } \\
\text { Calendaring } \\
\text { Meeting minutes (maintenance/distribution) } \\
\text { Meeting scheduling (set up) } \\
\text { Greeting, seeking participants, introduction and parting } \\
\text { Participant selection }\end{array}$ & 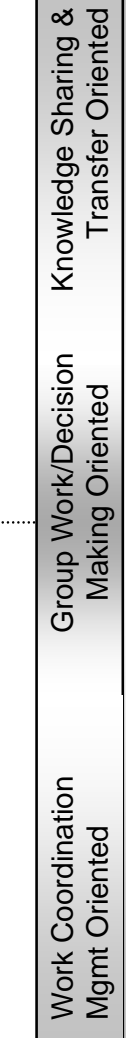 & 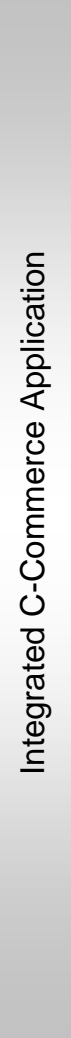 \\
\hline
\end{tabular}

Figure 1. A Framework for C-Commerce Application Development

\section{DEMONSTRATION OF THE FRAMEWORK}

Three typical c-commerce functions are used to demonstrate the usability of the framework. First, an example of the most structured collaborative activities is coordinating business transaction related activities performed through a value chain. The placement of a customer order could initiate manufacturing, raw material acquisition, back order processing, and shipment arrangement among collaborative members. To support this type of collaborative activity, participants must be selected, the goal of activity must be clearly shared among the participants, and fulfillment of the order should be treated as a mini-project. Thus, technologies such as workflow management, (email) notification, track project milestones/activities, to-do list, address book, calendaring, meeting minutes (maintenance/distribution), meeting scheduling (set 
up), greeting, seeking participants, introduction and parting, and participant selection should be integrated into a c-commerce application.

Second, an example of semi-structured collaborative activities is Collaborative Planning, Forecasting and Replenishment (CPFR). This type of collaborative activities requires functions that support a relatively structured group decision-making. Alternatives could be identified and criteria for evaluation need to be determined. Walkthrough could be an effective method to understand the effect of decision-making. Also, the decision making result must be summarized and clearly disseminated. In this case, decision-making applications may need to be shared by the members to collaboratively make a decision. Document management, document sharing, shared workspace and screen sharing can be useful to have common background information.

Finally, an example of unstructured collaborative activities is collaborative product design. In this kind of activities, knowledge sharing and learning becomes more critical. Also, conflict management plays a critical role because participants could represent different stakeholders with different interests. Design alternatives need to be produced from discussions rather than predefined models. Iterative try-and-error method may need to be supported to encourage creativity. Thus, technologies and systems such as knowledge management, group decision support, polling/survey, discussion (bulletin board), real-time talk (chat), video/audio conferencing, and group simultaneous authoring and revision become more useful.

\section{SUMMARY AND FUTURE RESEARCH}

This paper presented a framework for c-commerce application development that integrates generic collaborative computing and knowledge sharing functions into a c-commerce application. The framework was developed based on the classification of technologies, systems, and collaborative functional requirements identified in the previous research studies. Then, the paper demonstrated the usefulness of the framework. For future research, it is necessary to refine the classification of collaborative activity functional requirements and to conduct empirical studies to support fitness of technologies and system with them.

\section{REFERENCES}

1. Bafoutsou, G., \& Mentzas, G. (2002). Review and functional classification of collaborative systems. International Journal of Information Management, 22(4), 281-305.

2. Beckek, B. \& Brea, C. (2001). Deciphering Collaborative Commerce, Journal of Business Strategy, March-April, 36-38.

3. Bellini, H., Gravitt, J. P., \& Diana, D. (2001). The Birth of Collaborative Commerce, Salomon Smith Barney.

4. Binney, D. (2001), The knowledge management spectrum - understanding the KM landscape. Journal of Knowledge Management, 5(1), 33-42.

5. Chandler, H. E. (2001). The Complexity of Online Groups: A Case Study of Asynchronous Distributed Collaboration. ACM Journal of Computer Documentation, 25(1), 17-24.

6. Chen, Y.M., \& Liang, M.W. (2000). Design and Implementation of a Collaborative Engineering Information System for Allied Concurrent Engineering. International Journal of Computed Integrated Manufacturing, 16, 9-27. 
7. Chuang, T.-T. \& Nakatani, K. (2004). Planning and Deployment of Collaborative Commerce: A Conceptual Framework and Empirical Evidences. International Journal of Electronic Business, 2(2), 157 - 173.

8. DeFranco-Tommarello, J., \& Deek, F.P. (2004). Collaborative Problem Solving and Grouopware for Software Development. Information Systems Management, 21(1), 67-80.

9. Ferreira, J. \& Blonkvist, B. (2002). Directions in Collaborative Commerce: Managing the Extended Enterprise. Delloite Research. At http://www.dc.com/research.

10. Fou, J. (2001). Web Services and Collaborative Commerce: Collaborate or Die, 27 June, http://www.webservicesarchitect.com/content/articles/fou01 print.asp.

11. Gordon, J. R. (1993). A Diagnostic Approach to Organizational Behavior. Boston, MA: Allyn and Bacon.

12. Haggie, K. \& Kingston, J. (2003). Choosing Your Knowledge Management Strategy. Journal of Knowledge Management Practice, 4, http://www.tlainc.com/articl51.htm.

13. Himmelman, A.T. (1996). On the Theory and Practice of Transformational Collaboration: From Social Service to Social Justice. In Huxham (Ed.). Creating Collaborative Advantage. London: Sage Publications.

14. Holsapple, C. W. \& Singh, M. (2000). Toward a Unified View of Electronic Commerce, Electronic Business, and Collaborative Commerce: A Knowledge Management Approach. Knowledge and Process Management, 7(3), 151-164.

15. Marwick, A.D. (2001) Knowledge management technology. IBM Systems Journal, 40(4), 814-830.

16. Nonaka, I. \& Takeuchi, H. (1995). The Knowledge-Creating Company: How Japanese Companies Create the Dynamics of Innovation, New York, NY: Oxford University Press..

17. Olson, G. M., Olson, J. S., Carter, M., C., \& Storrosten, M. (1992). Small group design meetings: An analysis of collaboration. Human-computer Interaction, 7(2), 347-374.

18. Park, H., Suh, W., \& Lee, H. (2004). A role-driven component-oriented methodology for developing collaborative commerce systems. Information and Software Technology, 46(12), 819-837.

19. Shin, K. \& Lim, C.S. (2002). A Reference System for Internet Based Inter-Enterprise Electronic Commerce. Journal of Systems and Software, 60(3), 195-204.

20. Thuraisingham, B., Gupta, A., Bertino, E. \& Ferrari, E. (2002). Collaborative Commerce and Knowledge Management. Knowledge and Process Management, 9(1), 43-53.

21. Turban, E., McLean, E., \& Wetherbe, J. (2004). Information Technology for Management: Transforming Organizations in the Digital Economy. $4^{\text {th }}$ Edition. Hoboken, NJ: John Wiley and Sons, Inc.

22. van der Aalst, W.M.P. (1999). Process-Oriented Architectures for Electronic Commerce and Inter Organizational Workflow. Information Systems, 24(8), 639-671.

23. Warkentin, M., Bapna, R., \& Sugumaran, V. (2001). E-knowledge networks for interorganizational collaborative e-business. Logistics Information Management, 14(1/2), 149. 